\title{
Attention-deficit/hyperactivity disorder: seeking the right balance between over- and undertreatment
}

\author{
Pieter J. Hoekstra $\cdot$ Andrea Dietrich
}

Published online: 7 August 2014

(C) Springer-Verlag Berlin Heidelberg 2014

This issue of European Child and Adolescent Psychiatry contains an article that addresses functional impairments associated with subthreshold attention-deficit/hyperactivity disorder (ADHD) [2]. In a Korean nationwide community sample of 921 children, aged 8-11 years, the authors report that children with subthreshold ADHD were found to experience significant functional impairments, i.e., poorer behavioral and emotional control and worse academic performance compared to control children. Subthreshold ADHD was defined by the presence of at least three but no more than five inattentive or hyperactive/impulsive symptoms. However, whereas the diagnostic threshold $(\geq 6 / 9)$ for the DSM-IV symptoms represents a clear-cut operationalization for a diagnosis of ADHD, this disregards the fact that for the affected individuals and their parents the relevance of each symptom is likely to be different; for the diagnostic assessment as defined by the DSM-IV the symptoms are merely being counted, without taking the severity of each symptom into account. Furthermore, the subjective and objective impairment due to ADHD symptoms can in theory be greater in a child who fulfills only five symptoms in comparison to a child with six or more symptoms. These considerations illustrate how difficult it is to meaningfully operationalize thresholds for a spectrum disorder such as ADHD.

It is certainly an interesting approach to illustrate impairments in a subthreshold version of a disorder that has received so much coverage by media, politicians, and government due to concerns about overdiagnosis and

P. J. Hoekstra $(\square)$. A. Dietrich

Department of Psychiatry, University of Groningen, University

Medical Center Groningen, Hanzeplein 1-XA10,

9713 GZ Groningen, The Netherlands

e-mail: p.hoekstra@accare.nl overtreatment with medication, in particular psychostimulants. The article of Hong et al. [2] in this issue illustrates that there is not a simple clear-cut boundary between ADHD and 'normality', which we should be well-aware of, when considering concerns of possible overdiagnosis.

What is true, is that over the past decade, there has been a rapid and tremendous increase in the diagnosis of ADHD and in the use of medication treatments for ADHD within many European countries, in particular methylphenidate. This increase in the use of medication may be explained by several factors. First, better recognition and diagnosing of ADHD, in particular among girls. Second, the observation that children with ADHD receive the medication at a younger age than before. Third, it is now commonplace to receive the medication for many years, often during adolescent years and more and more into adulthood [4]. It is unclear, however, whether also children are being diagnosed and/or medicated in spite of falling below the diagnostic threshold set by DSM-IV ( $\geq 6 / 9$ criteria for either inattention or hyperactivity/impulsivity, or both) or failing to meet other aspects of the DSM-IV algorithm.

A second issue is that the increased and longer use of methylphenidate contrasts with the lack of long-term data on effectiveness. In fact, for example, the official Dutch multidisciplinary guidelines explicitly state that there is currently only evidence for the long-term effectiveness of methylphenidate for treatment duration between 3 months and 2 years. Much of our knowledge about treatment periods of longer than a year comes from following up a single study, the Multimodal Treatment of ADHD study (MTA) [12]. Earlier reports from the MTA study found that children taking stimulants alone or combined with behavioral treatment did better in the first year than children who got no special care or who got behavioral treatment alone. Later long-term reports from the MTA study tracked 485 
children for 8 years and found those still taking stimulant medication fared no better in the reduction of symptoms or in social functioning than those who had stopped medication [6]. Thus, the researchers wrote, "these long-term follow-up data fail to provide support for long-term advantage of medication treatment beyond 2 years for the majority of children." However, the long-term MTA data are purely observational and do not provide evidence for absence of ongoing effects of methylphenidate after many years. Given the high numbers of children using methylphenidate for many years, we definitely require solid data on the long-term effectiveness. The uncertainty of longterm benefits makes the treatment of ADHD an urgent public health matter (see for a review [3]).

A related problem concerns uncertainty about the current prescription practice of methylphenidate. This has resulted in increased levels of public concern; also, several reviews by professionals working in the field have attacked the widespread prescribing of methylphenidate (e.g. [14]) further increasing public disquiet [13]. Given, the rapidly increased prescription rates, there are now considerable doubts about proper assessment, indication, and appropriate conduct of long-term medication controls in clinical practice. On one hand, the current guidelines contain detailed recommendations about necessary steps to be taken prior to starting treatment with methylphenidate as well as necessary minimum standards of appropriate longterm controls, in terms of monitoring of side effects as well as critically assessing the continued indication for treatment with methylphenidate, but there is uncertainty whether these guidelines are adhered to appropriately in clinical practice.

There is also an urgent need in society to develop alternative treatment modalities for ADHD [8], beyond psychostimulant medication. As stated by Stevenson et al. [11], many families would prefer a nonpharmacological intervention if an effective one were available, given frequent concerns associated with medication use, with regard to the risk of altering children's personality by medicating them, but also with regard to adverse effects on sleep, appetite and growth and uncertainties about possible longterm adverse effects on the brain and cardiovascular system. Moreover, while psychostimulants have a well-established effectiveness in decreasing ADHD symptoms, there is little evidence that these drugs improve the academic achievement and accuracy in specific types of academic assignments of ADHD-diagnosed children [1, 7]. Studies have indicated that nutritional deficiencies may play a role in the cognitive deficits associated with ADHD (e.g., [5]). However, well-designed and powered randomized controlled trials (RCTs) addressing the role of broad-spectrum micronutrient supplements as a treatment for ADHD in children are currently lacking [9]. Intriguingly, a recent well-designed blinded RCT has shown large improvements in ADHD symptoms in adults after broad-spectrum micronutrient vitamin-mineral treatment [10]. The potential role of micronutrients as treatment for children with ADHD certainly deserves more well-conducted studies.

Finding the right balance between the possible overtreatment and the undertreatment of ADHD is of utmost priority for the field of child and adolescent psychiatry. There is currently less data than opinions on the matter and it is clear that more research is needed on the current prescription practice across Europe.

\section{References}

1. Advokat C (2010) What are the cognitive effects of stimulant medications? Emphasis on adults with attention-deficit/hyperactivity disorder (ADHD). Neurosci Biobehav Rev 34(8): 1256-1266

2. Hong SB, Dwyer D, Kim JW, Park EJ, Shin MS, Kim BN, Yoo HJ, Cho IH, Bhang SY, Hong YC, Pantelis C, Cho SC Subthreshold attention-deficit/hyperactivity disorder is associated with functional impairments across domains: a comprehensive analysis in a large-scale community study. Eur Child Adolesc Psychiatry (this issue)

3. van de Loo-Neus GH, Rommelse N, Buitelaar JK (2011) To stop or not to stop? How long should medication treatment of attention-deficit hyperactivity disorder be extended? Eur Neuropsychopharmacol 21(8):584-599

4. McCarthy S, Asherson P, Coghill D, Hollis C, Murray M, Potts L, Sayal K, de Soysa R, Taylor E, Williams T, Wong IC (2009) Attention-deficit hyperactivity disorder: treatment discontinuation in adolescents and young adults. $\mathrm{Br} \mathrm{J}$ Psychiatry 194(3):273-277

5. Mikirova NA, Rogers AM, Taylor PR, Hunninghake RE, Miranda-Massari JR, Gonzalez MJ (2013) Metabolic correction for attention deficit/hyperactivity disorder: a biochemical-physiological therapeutic approach. Funct Foods Health Dis 3(1):1-20

6. Molina BS, Hinshaw SP, Swanson JM, Arnold LE, Vitiello B, Jensen PS, Epstein JN, Hoza B, Hechtman L, Abikoff HB, Elliott GR, Greenhill LL, Newcorn JH, Wells KC, Wigal T, Gibbons RD, Hur K (2009) Houck PR; MTA Cooperative Group. The MTA at 8 years: prospective follow-up of children treated for combined-type ADHD in a multisite study. J Am Acad Child Adolesc Psychiatry 48(5):484-500

7. Prasad V, Brogan E, Mulvaney C, Grainge M, Stanton W, Sayal K (2013) How effective are drug treatments for children with ADHD at improving on-task behaviour and academic achievement in the school classroom? A systematic review and metaanalysis. Eur Child Adolesc Psychiatry 22(4):203-216

8. Rommelse N, Buitelaar J (2013) Is there a future for restricted elimination diets in ADHD clinical practice? Eur Child Adolesc Psychiatry 22:199-202

9. Rucklidge JJ, Kaplan BJ (2013) Broad-spectrum micronutrient formulas for the treatment of psychiatric symptoms: a systematic review. Expert Rev Neurother 13(1):49-73

10. Rucklidge JJ, Frampton CM, Gorman B, Boggis A (2014) Vitamin-mineral treatment of attention-deficit hyperactivity disorder in adults: double-blind randomised placebo-controlled trial. Br J Psychiatry 204:306-315

11. Stevenson J, Buitelaar J, Cortese S, Ferrin M, Konofal E, Lecendreux M, Simonoff E, Wong IC, Sonuga-Barke E (2014) 
Research review: the role of diet in the treatment of attentiondeficit/hyperactivity disorder-an appraisal of the evidence on efficacy and recommendations on the design of future studies. J Child Psychol Psychiatry 55(5):416-427

12. Swanson J, Arnold LE, Kraemer H, Hechtman L, Molina B, Hinshaw S, Vitiello B, Jensen P, Steinhoff K, Lerner M, Greenhill L, Abikoff H, Wells K, Epstein J, Elliott G, Newcorn J, Hoza B (2008) Wigal T; MTA Cooperative Group. Evidence, interpretation, and qualification from multiple reports of long- term outcomes in the Multimodal Treatment study of Children With ADHD (MTA): part I: executive summary. J Atten Disord 12(1):4-14

13. Timimi S (2003) Inappropriate use of psychostimulants. Br J Psychiatry $183: 173$

14. Zwi M, Ramchandani P, Joughin C (2000) Evidence and belief in ADHD. BMJ 321(7267):975-976 